\title{
Home Environment In Relation To Feeling of Security and Self Confidence of Adolescents
}

\author{
Sanju Verma ${ }^{1}$, Dr. Joginder Mukherjee ${ }^{2}$ \\ ${ }^{I}$ (M.Ed. Student, Department Of Education, Govt. College of Education, Chandigarh., India) \\ ${ }^{2}$ (Associate Professor, Department of Education, Govt. College of Education, Chandigarh, India)
}

\begin{abstract}
The present investigation endeavored to assess the relationship of home environment variable with the feeling of security and self confidence variables of adolescents. A sample of 100 adolescents was randomly selected from various government model senior secondary schools of Chandigarh, India. Researcher administered home environment inventory by Misra, security - insecurity scale by Shah and Agnihotri self confidence inventory to collect the relevant data. Karl Pearson coefficient of correlation was the statistical technique used for data analysis. Finding revealed that home environment has a significant relationship with feeling of security variable of adolescents but has no significant relationship with self confidence variable of adolescents. Based on the finding, some recommendations were made.
\end{abstract}

Keywords: Adolescents, Feeling of security, Home environment and self-confidence.

\section{Introduction}

Environment is the aggregate of various factors and stimulations which individual receives from conception till death. Good (1959) has described environment as a term designating all the objects, forces and conditions that affect the individual through and such stimuli as he is able to receive. Home plays an important role in moulding the personality of the children. Home is the first socializing agency where the child learns the patterns of behaviour prevalent in the community. Some of the early experiences leave indelible impression on the minds of children, which to a great extent continue influencing behaviour of children throughout life. The type of behaviour of parents, siblings and other members of the society also influence the child's growth. Since the home is the first institute therefore parents temperaments, behaviour, character and mutual relations influence child's personality development. Home environment include factors like socio- economic status, parents aspirations and expectations, parental attitude and socially determined expectations of family members from each other. Home environment is an important factor which directly or indirectly affects the feeling of security and self confidence of child where as an unfavourable environment can bring about a serious handicap in feeling of security and self-confidence of child.

Childhood is a period of rapid growth and development and is said to be the golden age for the building of personality. Further, adolescence years are said to be of critical importance in mental, social, emotional and physical growth and development. The mind, emotions and the body do not necessarily keep pace with each other in terms of chronological years of adolescence, as in infancy, concentration in one aspect of growth may means the neglect of another. In this context, home occupies the first and the most significant place for the development of the child. Inadequate home environment is likely to cripple the personality of the child from the point of his/her abilities and behaviour adjustments. Thus nature of environment provides the necessary sensory inputs, stimulation and experimental basis for the development of perceptual and cognitive skills in adolescents.

In light of the above, the present study intends to assess the home environment in relation to feeling of security and self- confidence of adolescents.

\section{Objectives}

1. To find out relationship of home environment variable with the feeling of security variable of adolescents.

2. To find out relationship of home environment variable with the self confidence variable of adolescents.

\section{Hypotheses}

1. There exists a significant relationship between home environment variable and feeling of security variable of adolescents.

2. There exists a significant relationship between home environment variable and self confidence variable of adolescents. 


\section{Method}

The method of convenient sampling was used for the identification of sample of 100 adolescents from class IX of Government Schools of Chandigarh.

The tools used to collect the relevant data were Agnihotri Self- Confidence Inventory (ASCI) by Agnihotri (1987), Home Environment Inventory (HEI) by Misra (1983) and Security- Insecurity Scale (SIS) by Shah (1989).

After all the necessary data was obtained from each of the selected tests used for the study, scores were tabulated for finding out the nature of the test scores of all the variables under consideration. The relevant statistical technique of Karl Pearson coefficient of correlation was used for the analysis of the data.

\section{Results}

The results were presented according to the posed research hypotheses as follows:

Hypothesis 1: There exists a significant relationship between home environment variable with feeling of security variable of adolescents.

Table 1 presents the coefficient of correlation of scores of ten dimensions i.e. control, protectiveness, punishment, conformity, social isolation, reward, deprivation of privileges, nurturance, rejection and permissiveness of home environment variable and total of home environment variable with feeling of security variable of adolescents.

\section{Table 1}

Coefficient of correlation of scores of ten dimensions of home environment variable and total of home environment variable with feeling of security variable

\begin{tabular}{|l|c|}
\hline \multicolumn{1}{|c|}{ Variables } & r-values \\
\hline Home environment (dimension (A)-Control) and Feeling of Security & $0.246^{*}$ \\
\hline Home environment (dimension (B)-Protectiveness) and Feeling of Security & $0.251^{*}$ \\
\hline Home environment (dimension (C)-Punishment) and Feeling of Security & 0.153 \\
\hline Home environment (dimension (D)-Conformity) and Feeling of Security & $0.209^{*}$ \\
\hline Home environment (dimension (E)-Social Isolation) and Feeling of Security & 0.172 \\
\hline Home environment (dimension (F)-Reward) and Feeling of Security & $0.350^{* *}$ \\
\hline Home environment (dimension (G)-Deprivation of Privileges) and Feeling of Security & 0.106 \\
\hline Home environment (dimension (H)-Nurturance) and Feeling of Security & $0.406^{* *}$ \\
\hline Home environment (dimension (I)-Rejection) and Feeling of Security & 0.129 \\
\hline Home environment (dimension (J)-Permissiveness) and Feeling of Security & $0.291^{* *}$ \\
\hline Home environment and Feeling of Security & $0.348^{* *}$ \\
\hline
\end{tabular}

$* *$ correlation is significant at 0.01 level (2-tailed)

*correlation is significant at 0.05 level (2-tailed)

The data above revealed that the $\mathrm{r}$ - values of $0.246,0.251$ and 0.209 shows that relationship between control, protectiveness and conformity dimensions of home environment and feeling of security are significant at 0.05 level, whereas the r-values of $0.350,0.406$ and 0.291 shows that relationship between reward, nurturance and permissiveness dimensions of home environment and feeling of security variable are significant at 0.01 level. The $\mathrm{r}$ - value of 0.348 shows that the relationship between total of home environment and feeling of security is significant at 0.01 level.

Hence, the hypothesis 1 namely, 'there exist a significant relationship between home environment and feeling of security of adolescents' has been retained.

Hypothesis 2: There exists a significant relationship between home environment variable with self confidence variable of adolescents.

Table 2 presents the coefficient of correlation of scores of ten dimensions i.e. control, protectiveness, punishment, conformity, social isolation, reward, deprivation of privileges, nurturance, rejection and permissiveness of home environment variable and total of home environment variable with self- confidence variable of adolescents.

Table 2

Coefficient of correlation of scores of ten dimensions of home environment variable and total of home environment variable with self confidence variable

\begin{tabular}{|l|c|}
\hline \multicolumn{1}{|c|}{ Variables } & r-values \\
\hline Home environment (dimension (A)-Control) and self confidence & 0.021 \\
\hline Home environment (dimension (B)-Protectiveness) and self confidence & -0.067 \\
\hline Home environment (dimension (C)-Punishment) and self confidence & 0.019 \\
\hline Home environment (dimension (D)-Conformity) and self confidence & 0.158 \\
\hline
\end{tabular}




\begin{tabular}{|l|c|}
\hline Home environment (dimension (E)-Social Isolation) and self confidence & 0.094 \\
\hline Home environment (dimension (F)-Reward) and self confidence & -0.052 \\
\hline Home environment (dimension (G)-Deprivation of Privileges) and self confidence & 0.007 \\
\hline Home environment (dimension (H)-Nurturance) and self confidence & -0.053 \\
\hline Home environment (dimension (I)-Rejection) and self confidence & 0.106 \\
\hline Home environment (dimension (J)-Permissiveness) and self confidence & -0.015 \\
\hline Home environment and self confidence & 0.026 \\
\hline
\end{tabular}

The data above revealed that the $\mathrm{r}-$ values of $0.021,-0.067,0.019,0.158,0.094,-0.052,0.007,-0.053$, 0.106 and -0.015 shows no significant relationship between the ten dimensions of home environment and self confidence variables. Also the r-value of 0.026 shows no significant relationship between the total of home environment and self confidence variable. This indicates that home environment has no effect on self confidence of adolescents.

Hence, the hypothesis 2 namely, 'there exist a significant relationship between home environment and self confidence of adolescents' has not been accepted.

\section{Discussion}

The analysis of the scores revealed that the relationship between control, protectiveness and conformity dimensions of home environment and feeling of security are significant at 0.05 level (i.e. P > 0.05), whereas the relationship between reward, nurturance and permissiveness dimensions of home environment and feeling of security variable are significant at 0.01 level (i.e. $\mathrm{P}>0.01$ ). The relationship between total of home environment and feeling of security is significant at 0.01 level (i.e. P > 0.01), meaning thereby that if home environment is improved, than it can enhance the feeling of security. This finding is in line with the report of Harvey (2000) who found that individuals with high levels of secure attachment perceive themselves as having a cohesive relationship with their families, as having adopted their family values in regard to intellectual and cultural activities, and are engaged in more active problem solving strategies to deal with the problems.

The r-values of ten dimensions of home environment and self confidence variable shows no significant relationship as $\mathrm{P}<0.05$ level of probability. The relationship between the total of home environment and self confidence variables is also not significant as $\mathrm{P}<0.05$ level of probability. This indicates that home environment has no effect on self confidence of adolescents.

\section{Conclusion}

The nature of the environment provides the necessary sensory inputs, stimulation and experimental basis for the development of the feeling of security of adolescents. When there is dearth of resources, lack of awareness, ignorance and illiteracy it may affect adolescents for developing their potential to the maximum. Inadequate home environment is likely to cripple the personality of child and kill his confidence from the point of his/her abilities and behaviour adjustment. Parents can play vital roles by improving their home environment, feeling of security and self- confidence.

\section{Recommendations}

From the findings of the study, the following recommendations are made:

1. Parents and teachers should use indigenously available and low cost material at home for encouragement of the adolescents to increase their potential.

2. To develop overall personality and enhance concentration, academic achievement, emotional stability of the child parents should provide love and attention at home.

\section{References}

[1] C.V. Good, Dictionary of education (Mc Graw Hills, NY, 1959) 334-351.

[2] R. Agnihotri, Agnihotri's Self Confidence Inventory (ASCI), National Psychology Corporation, Agra, 1987.

[3] K.S. Misra, Manual for Home Environment Inventory (HEI), Ankur Psychological Agency, Luckhnow, 1989.

[4] B. Shah, Security-Insecurity Scale (SIS), Ankur Psychological Agency, Luckhnow, 1989.

[5] M. Harvey, Relationship between adolescent's attachment style and family functioning, doctoral diss, Department of Psychology, University of Canterbury, New Zealand, 2000.

[6] K. B. Mc Elhaney, G.P. Kuperminc, Stability and change in attachement security across adolescents, Child Development, 75(6), 2004. 